not concerned with their health' needs to be approached with due care and appropriate understanding of human physiology - I'm sure we may all have come across obese or overweight individuals who may not necessarily agree with such generalised statements.

As your keen readers would have spotted in issue 10 (214: 489), the British Society of Periodontology is embarking upon a large campaign to raise awareness of periodontal diseases for both clinicians and patients, with particular emphasis on the systemic links. A recent joint workshop between leading world-renowned clinicians and researchers of the European Federation of Periodontology and the American Academy of Periodontology evaluated the entire evidence base in a systematic way (see www.efp.org for a comprehensive summary).

The association is indeed modest, with an Odds Ratio of $1.81,{ }^{1}$ but the biological plausibility is valid - obese patients are at a heightened constant state of systemic inflammation as well as at a high risk of insulin resistance, both of which we know can impact host immune responses hence its association with periodontal disease. ${ }^{2}$

When researchers started noticing a link between smoking and periodontal diseases, ${ }^{3}$ the association was put down to the assumption of poor oral hygiene, just as suggested here by $\mathrm{C}$. Marks. Well-conducted research by Bergström ${ }^{4}$ finally proved smoking as its own risk factor, and the rest, as they say, is history.

Therefore, may we suggest to our colleagues living in this world of evidence-based medicine and dentistry, that we allow our dedicated researchers to do what they do best, and await for further definitive research to give clinicians the fully-informed guidance we need on the management of periodontitis in overweight and obese patients.

M. Tank, O. Patel, S. Boghani, A. Al-Omar London

1. Suvan J, D'Aiuto F, Moles D, Petrie A, Donos N. Association between overweight/obesity and periodontitis in adults. A systematic review. Obes Rev 2011; 12: e381-404.

2. Linden G, Lyons A, Scannapieco F. Periodontal systemic associations: review of the evidence. J Clin Periodont 2013; 40 Suppl 14: S8-S19.

3. Pindborg J. Tobacco and gingivitis (I). J Dent Res
1947; 26: 261-264.

4. Bergström J, Preber H. Cigarette smoking in patients referred for periodontal treatment. Scan J Dent Res 1986: 94: 102-108.

DOI: 10.1038/sj.bdj.2013.749

\section{BIZARRE METAL SPLINT}

Sir, I recently saw a 64-year-old male patient who presented with pain from the lower left quadrant and requested an extraction of a retained root in this region.

On intraoral examination, to my amazement there was a bizarre metal splint covering all the teeth in both the upper and lower arches (Figs 1-2). This had been in place for over a year, as confirmed by the patient and judging by the amount of calculus visible.

The splints were constructed by the

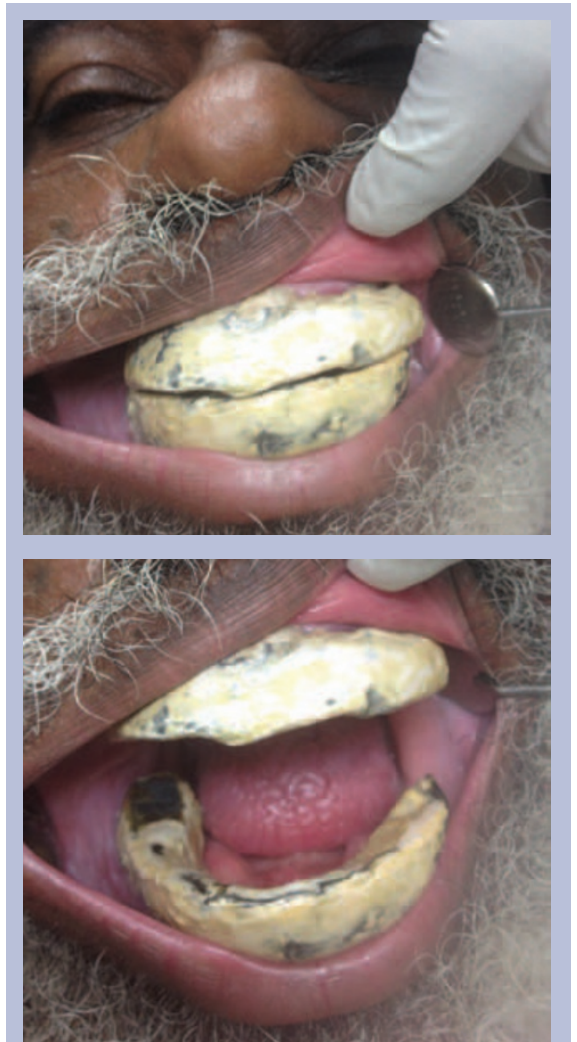

Figs 1-2 An engineer's home-made 'precious splint'

patient, a 'former engineer who was quite good with his hands'. He claimed the splints had helped to stabilise his mobile teeth, enabling him to chew food much better.

The retained root was not visible in the oral cavity, but an OPG X-ray revealed a retained root in the region of the 36 and the splints firmly secured in place (Fig. 3).

The irony of it all was that the patient

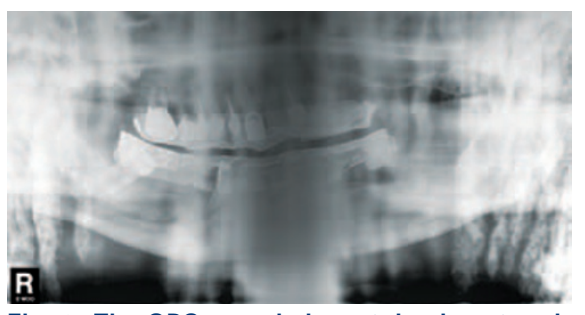

Fig. 3 The OPG revealed a retained root and the splints firmly secured in place

wanted the retained root removed, but his 'precious splint' kept intact at all times. The patient also failed to mention if he had attempted an extraction himself leaving a retained root behind.

We agreed that a hospital referral was in the patient's best interest, in case of any other underlying pathology.

Hopefully the hospital may have persuaded the patient to have the splints removed, which may have resulted in the removal of the underlying teeth, as the splints seemed firmly secured with some sort of strong cement.

The end result may be the provision of a denture after the extraction of the mobile teeth, unless the patient decides to construct a DIY implant himself!

Though homemade devices are rare in the UK this is an example of one such rare case.

V. Egemonye London

DOI: $10.1038 /$ sj.bdj.2013.750

\section{NOT AN IANB}

Sir, I have been successfully using a local anaesthetic (LA) technique introduced to me by Professor Brian Millar (King's Dental Institute, London) which is reliable, predictable and gives far greater patient comfort than inferior alveolar nerve blocks (IANBs). Painless IANBs are not always achievable, quick in onset or capable of achieving profound anaesthesia. ${ }^{1}$ There is also the potential for nerve damage independent of the LA used but especially associated with the use of articaine., ${ }^{2,3}$

Initially, I apply topical anaesthetic gel and give a buccal infiltration alongside the tooth I intend to anaesthetise. After waiting for onset of anaesthesia from the infiltration, I administer $0.1 \mathrm{ml}$ articaine $4 \%$ with 1:100,000 adrenaline (Septanest), both mesially and distally of the tooth to be treated, 